\title{
Leveraging Lean in the Office: Lean Office Needs a Novel and Differentiated Approach
}

\author{
Bruno G. Rüttimann'1, Urs P. Fischer2, Martin T. Stöckli ${ }^{3}$ \\ ${ }^{1}$ ETH-IWF, Zurich, Switzerland \\ ${ }^{2}$ Lean Solution, Zurich, Switzerland \\ ${ }^{3}$ Inspire AG, Zurich, Switzerland \\ Email: ruettimannbrunog@ethz.ch, urs.p.fischer@leansolution.com, stoeckli@inspire.ethz.ch
}

Received 18 August 2014; revised 16 September 2014; accepted 8 October 2014

Copyright (C) 2014 by authors and Scientific Research Publishing Inc.

This work is licensed under the Creative Commons Attribution International License (CC BY). http://creativecommons.org/licenses/by/4.0/

(c) $\underset{\mathrm{EY}}{\mathrm{B}}$ Open Access

\begin{abstract}
Lean Six Sigma tools have been increasingly employed also in the service industry, however with different success as field studies have shown. The reason not only has to be attributed to a poor Change Management, but can also be attributed to the intrinsic characteristics of the Lean techniques, which have been tailored to sustain a stable customer-takted pull-manufacturing principle. An office workplace shows significant differences to a procedural shop floor environment, as it comprises both, procedural and relational processes. The office environment, therefore, cannot be described by a purely transactional shop floor model-it necessitates a separate model, with a differenciated approach, which covers the procedural as well as the relational aspects of office tasks. Also the different characteristics of the transaction object as well as the operation transformation and process governance do not allow an un-adapted application of Toyota's comprehensive Lean toolset. The approach of Lean for the office environment needs a reinterpretation of the Lean logic and TPS Lean tools for the procedural part as well. Therefore, different and adapted approaches and tools are clearly necessary. The paper shows the objectives and principles of Lean and why Lean manufacturing is also interesting to be applied in the office environment. The differences between office and production jobs are detailed and introduce the problem of lean application in the office. The particular characteristics of the office environment are discussed and enable to enter into the Relational Office Model. Furthermore, we explain the paradigm shift which is necessary to take full benefit of the Lean approach in the office environment, however without presenting the reinterpreted office Lean toolset due to space reasons. This will be the topic of a next paper.
\end{abstract}

\section{Keywords}

Lean Manufacturing, Lean Office, Lean Approach, Lean Toolset, Service Industry 


\section{Introduction}

Productivity has become an absolute key characteristic since long not only for industry, but for services as well. In order to achieve operational excellence, managers use the Lean and Six Sigma tools that were initially developed for production purpose. In the office area, the results of this approach were quite mixed, and in many cases did not attain the expected results. Indeed, Lean tools may only be partly applied without major change, as the characteristics of the office processes are very different from the industrial manufacturing processes. These differences are worked out in a comparative analysis in terms of transaction objects, process characteristics and work execution. We sketch the specific properties and show that a reinterpretation of Lean tools is necessary for a Lean Office approach.

\section{Lean Objectives and Lean Principles}

The Toyota Productions System TPS [1] [2] introduced a new revolution in the industry that resulted into a significant increase in process efficiency. For quite some time, Lean in combination with Six Sigma and Business Process Management BPM has also found its way into the service sector [3] [4]. This is, indeed, not surprising as today more than $70 \%$ of the working population is engaged in administrative or service oriented activities and processes, not only, but very often, in the form of a desk job. Obviously, this means as well a huge improvement potential exists in the office environment [5]. While key indicators for production that are used every day, there exist only few key figures that measure the efficiency of office activities and processes. This is not because administrative processes are difficult to be measured, but because the execution of such processes can be interpreted by the executor rather freely and because Taylorism has not yet found its way into the office. This hides away a large cost improvement potential through standardization of activities and processes as well as the search for inefficiencies that represents waste or Muda, as the Japanese call it. Eliminating waste, however, is just one of the key tasks in the Lean Six Sigma (LSS) methodology. As desk jobs are connected to people and the main cost factor in the western service sector are labor cost, it is obvious that forward-looking managers of service firms as banks, insurances, telecoms, hospitals as well as public authorities want to make use of these new methods and management approaches. Thereby, these tools and methods developed for the industrial manufacturing area are transferred in most cases without change or adaptation to the office world, which is characterized by completely different activities and processes. Even though in administrative processes ultimately the same objectives are pursued as in industrial processes (Figure 1), some Lean principles as material-flow and customer-pull concepts can only be applied in a rudimentary manner. Therefore, the traditional Lean philosophy gets a different dimension in the administrative area with reduced exploitation of the available potential, but the importance remains however unreduced. This is the starting point that leads to a differentiated consideration of Lean in the service environment compared to its application in the industrial world. Until now, this has only partly been recognized and even not solved [6] or at least addressed and first attempts are made to be solved [7].

A joint study made by inspire/ETH and SISE about the prevalence of Lean and Six Sigma in industrial and service companies in Switzerland [8] has shown that different approaches are used to achieve business excellence. Services mainly use a mixed LSS-DMAIC approach. This finding and others clearly imply that the original Lean philosophy, as developed and applied by Toyota in its TPS, was not fully understood by the western world — not by the industry and not at all by the service sector. That makes it even more necessary to elaborate the differences between these two sectors in order to define a Lean philosophy that is optimized for services.

\section{Major Differences between Office Jobs and Production Jobs}

Before we enter into the transfer of Lean and Six Sigma toolsets to the office activities we need to understand and characterize the desk job and to generate a model of it. The process landscape can be grouped into the following three categories:

- Category Operational Processes (i.e. production and service generation);

- Category Support Processes (i.e. sourcing, HR, accounting, maintenance);

- Category Management Processes (as corporate governance, strategy development, risk management, budgeting).

The traditional Lean Six Sigma community distinguishes, however, only between two types of processes:

- Manufacturing processes;

- Transactional processes. 


Approach
-Identify and map value streams
- Eliminate waste
- Introduce 1-piece flow on customer pull
- Empower people
- Strive for continuous improvement
Objectives
- Eliminate waste (TIMEWOODS)
- Shorten process leadtime
- Minimize total cost
Figure 1. Lean philosophy.

This distinction is, however, too simplified, as we will outline later. The transactional environment requires a further differentiation of all transactional processes. Indeed, solely the operational transaction processes are similar to the manufacturing processes and mainly for those we could apply continuous flow production considerations and realize cell design, but even this requires a re-interpretation of the original Lean concepts.

As transactional processes, we usually understand not only the operational, but also the service generation processes, and all office, administration, and supportive processes. The transactional process types are prevailing in an enterprise and thus require a particular attention. In general, the transactional processes are represented generally by swim lane type graphics in order to visualize the interfaces which represent hand-overs; for shop floor production processes, however, typically VSM value stream mapping charts are used, which focus on work in process. Also mixed forms in representation are common and useful.

A comparison between production and transactional processes (operations, support, governance) in relation to the transaction object, the process characteristics and the work execution is necessary in order to understand the differences between manufacturing and office processes. Figure 2 and Figure 3 show a simplified comparison. The two processes differ strongly in product and information flow and particularly in the service provision. Although the support processes are implicitly or explicitly (Q handbook) defined as well, they show a much smaller degree of standardization of their activities in comparison to manufacturing processes and are much more subject to randomness as a consequence of the freedom of execution and external influences. This is also related to the characteristics of the transaction object. The physical product is defined based on customer specifications, or for shelf products according to internal specifications, in a "deterministic manner" and the product manufacturing process has to be exactly repeatable ("identical repeatability"). In contrast, the performance of a service is determined "parametrically" and represents through the uniqueness of each of its specification at best a "formal repeatability" that relates to the repetition of the process, but not to the content. At best, the required information processing has a wide spectrum, which reaches from filling out a given form (i.e. structured IT-controlled order entry) to a completely unstructured "Voice of the Customer" (VOC) information (i.e. oral instruction by the line manager). Therefore, it corresponds more to a relational than to a procedural transaction. Another difference exists in the capital intensity of the required infrastructure and therefore also the attention that is given to a maximal usage of the equipment (Total Productive Maintenance TPM with the Overall Equipment Effectiveness, the OEE metric, KPI which is applied only to equipment and not to people).

ROI key figures play a minor role in service companies in comparison to industrial firms with a large asset base. In services, the productivity of the employees is key—not the productivity of the equipment as in the industry. Furthermore, due to the required decisions, any human activity represents a characteristic that is at the discretion of the executor and leads to, let us call it, the absence of "identical repeatability" (keyword gage R\&R). Exactly this lack of "identical repeatability" in most of the processes will lead us towards a different modeling of the desk job, one that is more form-like (functional and relational instead of procedural), i.e. defined by the target instead of deterministically prescribing. Figure 4 highlights the relevant structural differences between the production and transaction processes. It is well possible, however, that we also find some repetitive and structured processes in the transactional area that represent a typical procedural sequence comparable to those in the shop floor. In the focus of the reinterpreted office model stands a paradigm change from work-content oriented production activity to work-target oriented office activity.

Due to the fact that we have to achieve in manufacturing a customer defined takt, work content of the processes is reduced to small repeatable elements that increase efficiency enormously (Taylor's division of labor). In the transactional processes of the office world, only a limited sequencing of the work, distributed among 


\begin{tabular}{|c|c|c|}
\hline & Shopfloor & Office \\
\hline Transaction object & Physical product & Service, file, information \\
\hline Morphology & Tangible, visible & Intangible, invisible \\
\hline Product definition & $\begin{array}{l}\text { Determined according to } \\
\text { defined specification }\end{array}$ & $\begin{array}{l}\text { Ranging from parametric } \\
\text { defined template to VOC }\end{array}$ \\
\hline Product variation & None & Virtually unlimited \\
\hline Product quantity & Virtually unlimited batch size & Single transaction batch size \\
\hline Product non-conformity & $\begin{array}{l}\text { Visible with defined out of } \\
\text { control procedure }\end{array}$ & $\begin{array}{l}\text { Break, often invisible, } \\
\text { undefined mitigation }\end{array}$ \\
\hline Degree of control & High (directly influenced) & Low (externally influenced) \\
\hline Predominant actions & Executing & Analyzing/planning/executing \\
\hline Make to & Make to stock possible & Make to order \\
\hline Assets & $\begin{array}{l}\text { Mainly product specific } \\
\text { equipment, capital intensive }\end{array}$ & $\begin{array}{l}\text { No task specific equipment, IT } \\
\text { is integrating backbone }\end{array}$ \\
\hline Set-up cost & Maybe relevant & Low, but task switch-over \\
\hline
\end{tabular}

Figure 2. Differences of transaction object.

\begin{tabular}{|c|c|c|}
\hline & Shopfloor & Office \\
\hline Principle orientation & $\begin{array}{l}\text { Process-centric } \\
\text { (task-oriented) }\end{array}$ & $\begin{array}{l}\text { Output-centric } \\
\text { (result-oriented) }\end{array}$ \\
\hline Transformation model & Procedural type & Relational type predominant \\
\hline Task description & $\begin{array}{l}\text { Detailed SOP including time } \\
\text { to comply with customer takt }\end{array}$ & $\begin{array}{l}\text { Approximate, rather description } \\
\text { of output to be performed }\end{array}$ \\
\hline Task characteristic & $\begin{array}{l}\text { Very structured, no degree of } \\
\text { freedom, no alternatives }\end{array}$ & $\begin{array}{l}\text { Less-structured, allows execution } \\
\text { discretionality, many alternatives }\end{array}$ \\
\hline Task content (width) & $\begin{array}{l}\text { Simple, confined } \\
\text { (narrow, to be takted) }\end{array}$ & $\begin{array}{l}\text { Complex, comprehensive (large } \\
\text { content, difficult to be takted) }\end{array}$ \\
\hline Waste, Value stream & Visible & Mainly invisible \\
\hline Value add & Usually transformation time & Includes think, write, listen, talk \\
\hline Process flow & Ideally 1-piece flow & Mainly push on "boss"-pull \\
\hline Process concept & Usually sequential steps & Random access to ressources \\
\hline Process aim & Balanced and takted flow & Maximize parallelization \\
\hline
\end{tabular}

Figure 3. Differences in process execution.

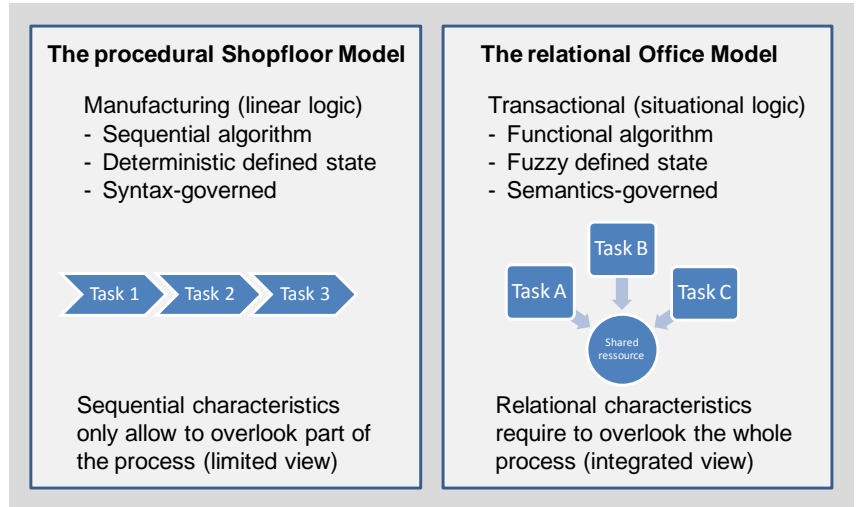

Figure 4. Synoptic comparison-shopfloor vs. office.

several persons, takes place. Even if a division is made, it has mostly functional character, the work content is not exactly defined and process alternatives exist. Therefore, even a "formal repeatability" may be missing. This means that the person in charge has a larger area of tasks and therefore some "enriched" job. This should also improve work quality, because less hand-overs happen that require information exchange. This is clearly necessary, as many repetitive work processes are identical, but the work objects, the information for every new order, 
is changing. The primary transaction object in the office is the file which needs additional information as input for the production of the service itself or for performing secondary clarification processes. This discrepancy is the reason why the introduction of a takted-pull system in the office would be inefficient, unnatural, difficult or even impossible to implement. That is why the TPS for service companies has to be newly interpreted, whereby Lean is getting a different, i.e. reduced meaning.

\section{The Relational Office Model}

In contrast to the production workplace the activities at an office workplace are manifold and much less repetitive. The differences can be summarized as follows:

- Non structured versus structured (work of an employee that follows Q-handbook instructions);

- Non controllable versus controllable (transparent insight for the line manager);

- Unique versus repetitive (repeatability and learning effect of the task);

- Manifold/complex versus monotonous/simple (work content);

- Alone versus in team (work scope);

- Entire versus part of a process (inter-functional labor division).

Indeed, the production activities are limited to a few, exactly structured and in terms of timing predetermined processes at one workplace in order to comply with the customer tact, such as:

- Operate;

- Monitor;

- Recognize;

- Give feedback/act,

which contains a very executing character. They are supportive to the Jidoka-principle and need therefore a rigid "wired control logic" in order to produce quality.

The activities in an office are more complex. Therefore, they need to be prescribed in a less deterministic way due to the variability of the input. Due to the large scope of the potential events, the work of the managers consists mainly in the following activities:

- Confront, recognize;

- Think;

- Decide;

- Act/communicate (write, read, call, discuss).

And for the assisting person in charge:

- Search documents/records (biggest non value-add position);

- Reflect;

- Copy/scan;

- Fill-out;

- Conclude/execute;

- Inquire/check;

- Document;

- Archive;

- Communicate.

This supposes to a large extent a "programmable logic" to control the processes, although here, in some areas, a fixed wired logic would be required as well as to achieve the intended quality. It is particularly important to reach and hold the required quality of processes and products, which is called reproducibility in manufacturing. Although office activities have a certain resemblance to the executing character of the production, the content and the provision of performance is clearly different. Whether an office activity contains more "thinking/deciding" or more "implementing/executing" content, depends mainly on the position of the employee. While the repetitive/executive activity dominates in production, we find a stronger verticalization of hierarchy and work content in the office area. The higher the position, the more the work content is unstructured and exogenously determined, the more executing the position, the more structured and repetitive the activities are. Therefore, we mainly find on the lowest hierarchical level task-centric process orientation of the executing person in charge (e.g. back office) similar to the production that strongly contrast with the result-oriented view of a manager, an assistant or a staff person. These differences are summarized in Figure 5, which outlines the governance of the execution logic. Very interesting is the approach of Kahneman [9]: The repetitive, automatically executed tasks 


\begin{tabular}{|c|c|c|}
\hline & Shopfloor & Office \\
\hline Kahneman thinking logic & System 1 (subconscious) & System 2 (explicit) \\
\hline Flexibility logic & Wired & Programmable \\
\hline Execution liberty & Very low (SOP-driven) & High (or template-driven) \\
\hline Person's function & Support to process & Main actor of process \\
\hline Execution & Very structured & Contingent approach \\
\hline Measurability & Easy & More difficult \\
\hline Disturbance noise & Limited, mainly endogen & Heavy, mainly exogen \\
\hline Control & Implicit (poka yoke, kata) & $\begin{array}{l}\text { Difficult, because often } \\
\text { hidden and high variety }\end{array}$ \\
\hline Consequence & $\begin{array}{l}\text { No degree of freedom } \\
\text { assuring repeatable and } \\
\text { reproducable quality }\end{array}$ & $\begin{array}{l}\text { High degree of freedom } \\
\text { how to perform the task to } \\
\text { get the output }\end{array}$ \\
\hline Out-of-control cases & Very limited & More frequent \\
\hline Focus & Efficiency & Effectiveness \\
\hline
\end{tabular}

Figure 5. Difference in work governance.

in production can be considered, "System 1 Processes", which are controlled by the unconscious. In the Toyota philosophy they correspond to "Kata". The activities in the office require a higher consciousness in order to complete the tasks; the person in charge has to work dedicated and in a focused manner. This conscious acting corresponds to "System 2 Processes". Here we can see the importance of the human resource; the person is required for "exception handling" and solving any problems that often appear. In the industrial language we would call this mastering "out of control" situations, i.e. applied to office, recognizing a wrong accounting entry, interpreting and correcting it.

As outlined already in the previous section, the office job has more functional/relational characteristics. That means, compared to a shopfloor job, the office job has rather a black box characteristic, whereas the shopfloor job has to be defined with the transparency of a white box approach. Indeed, the emphasis is not put on the way how to execute a job, but rather on what the desired output should be. This leaves to the office employee more freedom of action in job execution. The interaction with other stakeholders is therefore more relational than procedural. This is necessary because often additional information is required to execute properly the job due to the high variability of the initial input scope and perhaps incomplete information at this stage which require clarification, clarification which emerged only during the process execution. Exactly this aspect also requires that employees need a higher degree of education compared to shopfloor workers. Whether it is possible to force higher educated office employees in the rigid scheme of Lean standardized work is another issue which we will not discuss here. In addition, the "noise factor", e.g. telephone calls, is also much higher than in the shopfloor environment. All these factors make it necessary to talking, in general, of a Relational Office Model as depicted in Figure 6. Therefore, in the focus of the reinterpreted office model stands a paradigm change from work-content oriented production activity to work-target oriented office activity.

Hence we observe in transactional environments various process types, such as:

- Operational processes (executing value generating routine tasks);

- Supporting processes (executing other routine tasks);

- Execution processes (executing tasks that are non routine);

- Decision processes (comparing solutions and quantifying results);

- Planning processes (preparing an organizational implementation);

- Problem solving processes (analyze symptoms, identify causes, and find solutions).

In fact, only pure operational processes (hereunder fall the value adding transformational processes) as well as supporting processes (rather non value-adding administrative tasks like book keeping) can be compared with the procedural processes and even these only, if they have enough repetitive content. A characteristic of the process character may be:

- Unique (little structured);

- Repetitive (structured with a given sequence);

- Iterative (as a special case between unique and repetitive.

Apart from the repeating processes, also the iterative processes are very interesting, as those offer usually a 


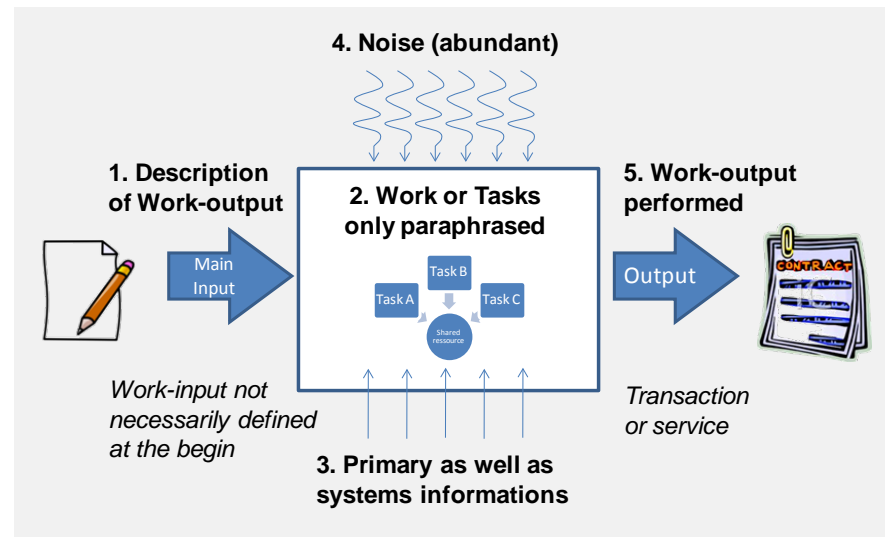

Figure 6. The relational office model.

high improvement potential. The administrative processes fall mainly in repetitive process characteristics, the problem solving processes into unique, if they are not solved using standardized problem solving procedures and if the problem description is not structured. Decision processes fall as well in the unique process category, if they are not part of a larger process, i.e. budgeting, which often have iterative characteristics, where the decision can be reduced to a simple "fixed-wired logic". Iterative processes should not be mixed-up with repetitive processes, although in some cases a similar work step can be repeated many times. An iterative process can be repetitive, if it occurs regularly (budgeting). A process must be a sequence of repetitive activities in order to be comparable to a classical procedural production process. Here one can apply a traditional Lean Six Sigma approach. In summary, the category of improvement techniques is determined by the process characteristics. The following dimensions have to be considered:

- Process frequency (unique versus repetitive);

- Number of process steps (one versus many);

- Recursivity of the process steps (unique versus multi times);

- Clarity of the output definition (unclear versus clear).

Figure 7 takes the first two dimensions and shows the spectrum of improvement approaches that reach from a "one-off task" (unique and integrated task) to an organized process (in the sense of a repetitive multi-step procedure spread over several persons and different departments). The applicability of the classical TPS and of the LSS approach for procedural processes is mainly in the upper-right quadrant; for all other, more relational processes, alternative approaches are required. The figure shows how variegated the process landscape in the office looks like. For the lower-left quadrant other methods of approaches have to be applied.

\section{A Paradigm Shift Is Required}

With a few exceptions, the application of Lean tools in the service sector is currently limited to value stream mapping of procedural process type of transactions, highlighting the distinction between value-adding and non value-adding activities and the search for waste. In fact, this is a very restrictive conception of the Lean office ideas of the original TPS as it is applied in manufacturing industries and covers also only a limited part of the potential office process type landscape. We have to recognize, however, that the classical Toyota Lean approach cannot be transferred into the transactional world in an unrestrained manner. Or how should one apply, i.e. TPM (management of maintenance), SMED (set-up time optimization), and Kanban-Pull in an office environment that is characterized by a high degree of "Mura" (variability)? Indeed, these very important Lean tools usually are not applied in transactional environments. But exactly these tools are necessary to implement a flawless customer-pull triggered single piece flow. Therefore, when people are talking about Lean office they do not exploit the full potential of Lean as a whole. In order to do so, the specific characteristics of the office way to work need to be taken into consideration. A re-interpretation of the Lean principles and tools for the office environment imposes itself. In this context it is important to understand that Lean is not just a tool-set but a complete tool-system, from which all tools fulfill a target-oriented, specific, but synergic purpose as depicted in Figure 8. Indeed, it is not the introduction of Kanban the ultimate target in the TPS Lean, as often pretended, but the im- 


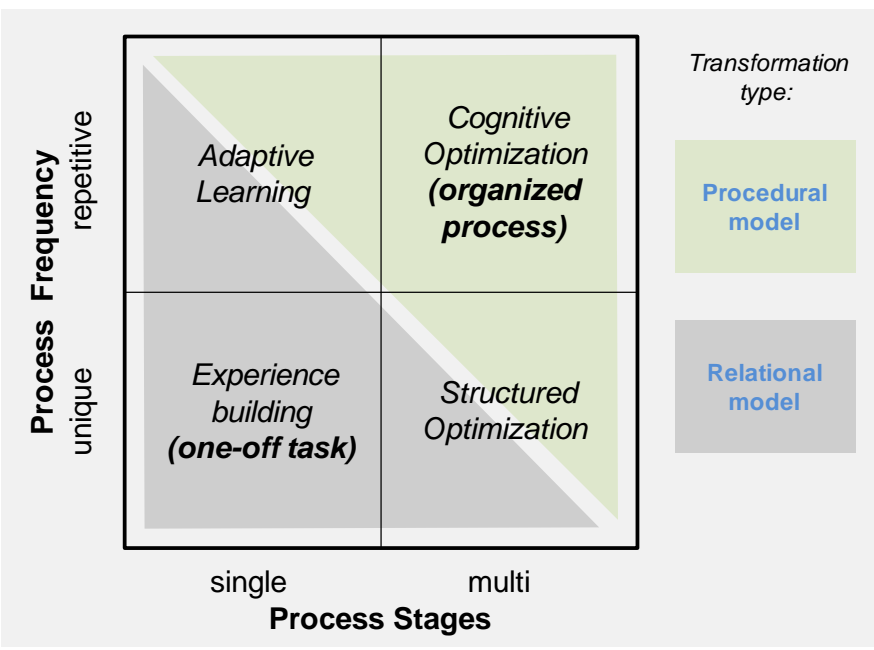

Figure 7. Transformation type and improvement approach in function of process character.

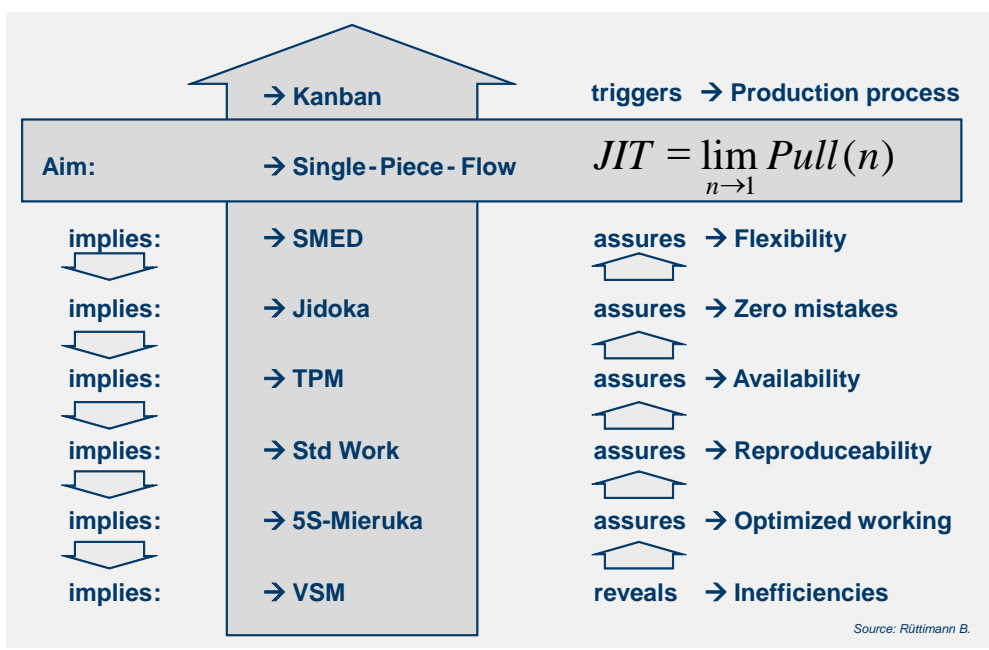

Figure 8. Lean is not a toolset; Lean is a tool system.

plementation of continuous flow production, which is activated through Kanban. In addition, other elements are required too for a well working continuous flow production, elements that form a system and are prerequisites for a single piece flow production. For example, set-up time reduction will not only reduce unproductive cost and does not only lead to additional capacity, but is required in the TPS Lean in order to reduce lot sizes in order to manufacture just-in-time. As another example, TPM is usually implemented to increase capacity by increased machine availability. But TPM in Lean is originally used to guarantee operability of the equipment within a single piece flow production system, where no "Just-in-case" breakdown process-decoupling safety buffers are available. The Lean toolset of the ultimate Lean philosophy is not just a toolbox from which to choose the appropriate tool, as often reported, it is a tool system! The real problem is that the complete classical Lean approach that has revolutionized the manufacturing industry can only be applied in a limited part to the service sector, and even there, only if we re-interpret its targets, which we will not outline further in this article. Therefore, a paradigm shift is required that takes into account the specificities of the performance provision and the execution of the tasks in the service sector. The remaining application field reduces the usage of the Lean approach in the office particularly to the elimination of waste, if we do not adapt present tools or develop ad-hoc tools as well as methods which model the relational office properties in an optimal way. This clearly shows that we need for Lean Office new and differentiated approaches and methods. Nevertheless, this does not preclude to begin with VSM and the elimination of Muda. 
Apart from the theoretical elements and techniques for implementation of a pull-production philosophy, also the Kaizen philosophy is often misunderstood. The original Kaizen idea of the TPS has little in common with the "Blitz-Kaizen"; a concentrated action of problem solving that is often applied in western service companies. Kaizen in its original sense involves all employees, who develop a continuous improvement process in autonomous teams. But exactly the original Kaizen could also perfectly be applied in service companies. In this context, the mindset of the management and how the re-orientation is implemented plays a decisive role for the success of the Business Excellence approach: Not the will is the driver, but the doing. And without effective change management, Lean Office will just be wishful thinking.

\section{Conclusion}

Experience shows that Lean is often misunderstood and usually used in a very limited manner in service companies - therefore, the high expectations set in Lean and Six Sigma will not be fulfilled. The comparisons made in this paper give an insight of the differences in process and job characteristics between manufacturing and service industries. It shows how we set a high importance on new and adapted Lean tools and concepts for the office to exploit the huge improvement potential hidden in the service industry and which can be addressed by adapted Lean Office tools. Such new and adapted tools, as well as approaches, for Lean Office are currently being elaborated by the authors.

\section{References}

[1] Ohno, T. (1988) Toyota Production System—Beyond Large Scale Production. Productivity Press, New York.

[2] Womack, J.P., Jones, D.T. and Roos, D. (1990) The Machine That Changed the World. Free Press, New York.

[3] George, M.L. (2003) Lean Six Sigma for Service. McGraw-Hill, New York.

[4] Association for Manufacturing Excellence (2007) Lean Administration-Case Studies in Leadership and Improvement. Productivity Press, New York.

[5] Rüttimann, B.G., Fischer, U.P. and Stöckli, M.T. (2011) Aufstieg und Fall von Six Sigma... oder warum heute Lean wichtiger ist. iO new Management, Springer, Axel Springer Schweiz, Zurich.

[6] Chen, J.C. and Cox, R.A. (2012) Value Stream Management for Lean Office-A Case Study. American Journal of Industrial and Business Management, 2, 17-19.

[7] Bonaccorsi, A., Carmignani, G. and Zammori, F. (2011) Service Value Stream Mapping (SVSM): Developing Lean Thinking in the Service Industry. Journal of Service Science and Management, 4, 428-439.

[8] Rüttimann, B., Waldner, H., Adam, M. And Stöckli, M. (2012) Lean Six Sigma in der Schweiz-Explorative Studie zur Standortbestimmung. Inspire/ETH, SISE.

[9] Kahneman, D. (2012) Thinking, Fast and Slow. Penguin Books, London. 
Scientific Research Publishing (SCIRP) is one of the largest Open Access journal publishers. It is currently publishing more than 200 open access, online, peer-reviewed journals covering a wide range of academic disciplines. SCIRP serves the worldwide academic communities and contributes to the progress and application of science with its publication.

Other selected journals from SCIRP are listed as below. Submit your manuscript to us via either submit@scirp.org or Online Submission Portal.
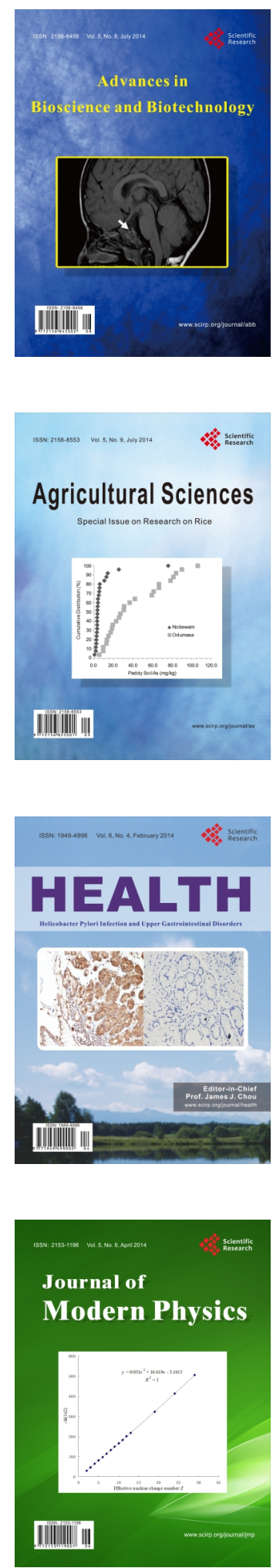
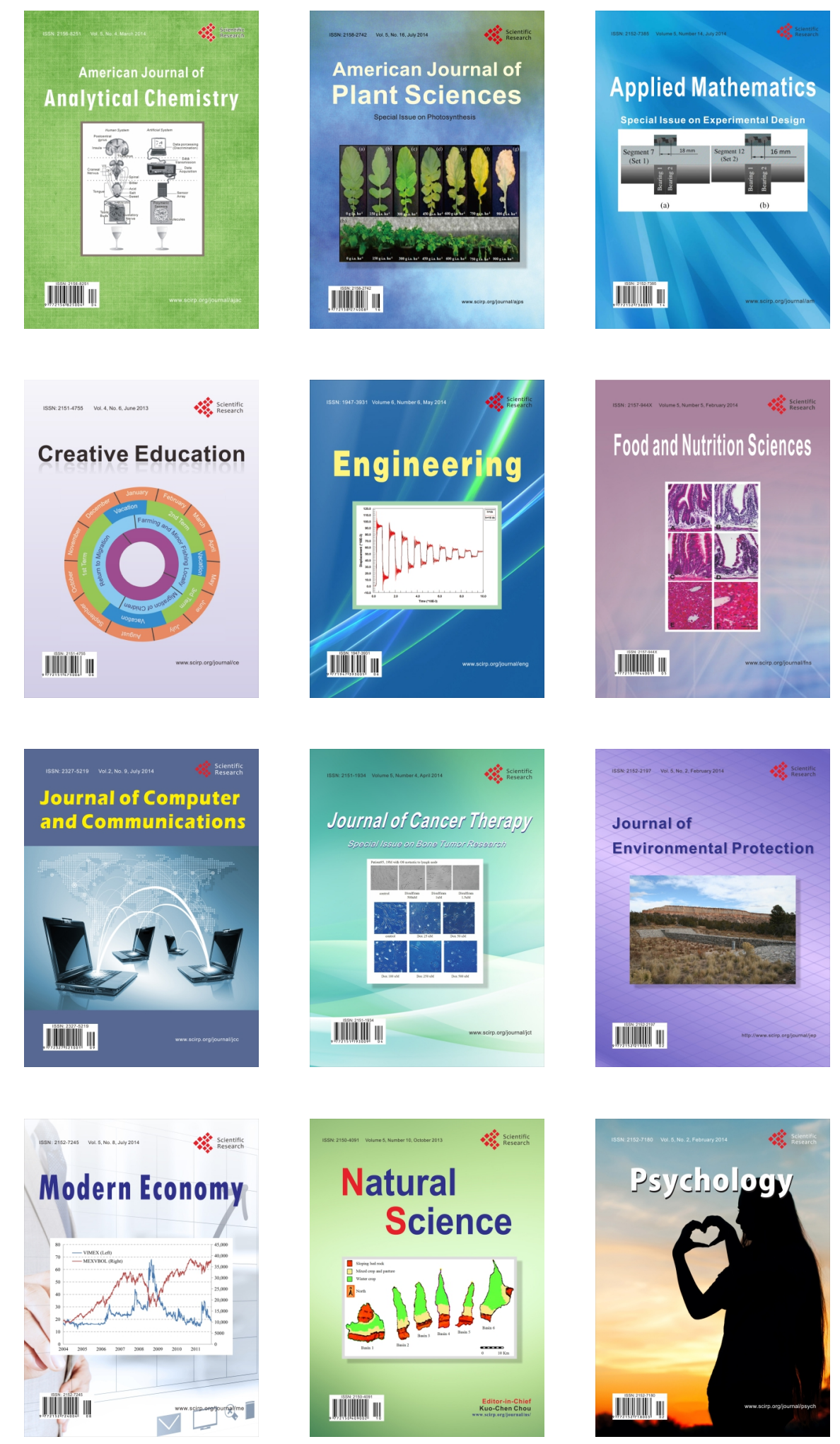